\title{
A inteligência competitiva associada ao alinhamento estratégico entre negócio e projetos de Tecnologia da Informação
}

\author{
Competitive intelligence associated with the strategic alignment \\ between business and information technology projects
}

\author{
Cássio Chagas Montenegro \\ Duarte \\ mtnegro87@hotmail.com \\ Pontifícia Universidade \\ Católica de São Paulo - \\ PUC-SP
}

\begin{abstract}
Resumo
A Tecnologia da Informação (TI), até recentemente, era vista apenas como um recurso operacional de suporte às atividades de negócio das organizações. Entretanto, devido ao aumento da competição, causada principalmente pela globalização, a TI tornou-se um fator estratégico à alta gestão, pois permite o processamento de grande quantidade de informação, num pequeno período de tempo. Assim, adquiriu um status diferenciado, como ferramenta de apoio ao planejamento estratégico da empresa. Diversos estudos sugerem que as empresas tornam-se mais competitivas conforme o maior grau de alinhamento entre suas estratégicas de negócio e TI. Nesse sentido, o artigo destaca a utilização da Inteligência Competitiva (IC) como um instrumento indutor de novas técnicas de gestão, que permite aos clientes expandirem as possibilidades de utilização de projetos. Dessa forma, a pesquisa baseou-se num estudo de caso realizado numa grande empresa prestadora de serviços de Tecnologia da Informação para órgãos públicos e privados do estado de São Paulo.
\end{abstract}

Palavras-chave: Alinhamento Estratégico, Gerenciamento de Projetos, Inteligência Competitiva.

\begin{abstract}
The Information Technology (IT), until recently, was only seen as an operational capability to support the organizations business activities. However, due to increased competition, mainly caused by globalization, IT has become a strategic factor to the high management, it allows the processing of large amount of information in a short period of time. Thus acquired a different status, such as support for strategic planning tool. Several studies suggest that companies become more competitive as the highest degree of alignment between its strategic business and IT. In this sense, the article highlights the use of Competitive Intelligence (CI) as an induction tool for new management techniques, which enables customers to expand the possibilities of using projects. Thus, the research was based on a case study conducted in a large company providing Information Technology services to public and private agencies, the state of São Paulo.
\end{abstract}

Keywords: Alignment, Project Management, Competitive Intelligence.

\section{Introdução}

O objetivo principal deste trabalho é estabelecer uma associação entre a Inteligência Competitiva(IC) e o gerenciamento de projetos de Tecnologia da Informação (TI), além de colaborar para o aprofundamento do conhecimento relacionado ao universo das técnicas de gerenciamento de projetos.

De forma a direcionar a realização da pesquisa, foi colocada a questão principal: como estabelecer a aproximação entre a IC e o gerenciamento de projetos de TI?

O estudo foi conduzido por meio de uma abordagem qualitativa, com a realização de uma revisão bibliográfica, complementada pela realização de pesquisa empírica, cujo objetivo foi observar o fenômeno, a fim de descobrir aspectos importantes relacionados à questão principal. 
O levantamento bibliográfico apresenta conceitos teóricos relacionados ao alinhamento estratégico entre negócio, Tecnologia da Informação e Inteligência Competitiva, como instrumento indutor de novas técnicas ao gerenciamento de projetos.

Na pesquisa empírica, o trabalho procurou identificar e analisar, por meio do método de estudo de caso, a forma pela qual o gerenciamento de projetos pode associar-se à IC.

Na conclusão, o artigo propõe a utilização da IC como uma ferramenta que permita aos clientes expandirem as possibilidades de utilização dos requisitos de projetos, ao integrá-los aos seus próprios recursos, habilidades e competências, a fim de fomentar outros bens, ou serviços, complementares e derivativos.

\section{Revisão da Literatura}

Segundo Henderson e Venkatraman (1989), apesar da ampla abordagem de que as estratégias de negócio e TI devem estar alinhadas, ainda é pouco explorada pela literatura uma forma prática pela qual esse alinhamento possa ser atingido: "O conceito de alinhamento tem sido invocado, historicamente, como metáfora para defender a integração entre as estratégias de Tecnologia da Informação, e de negócios, sem adequada articulação, ou esclarecimento, de suas características".

A aplicação de conceitos como ajuste estratégico dos recursos às oportunidades, ou estratégias genéricas de baixo custo versus a diferenciação em relação ao foco, além da hierarquia de metas estratégicas, podem tornar o processo de planejamento estratégico rígido. Essa rigidez tem um impacto negativo sobre a organização (HAMEL; PRAHALAD, 1990).

Para o contexto de TI, as estratégias de negócios da empresa devem refletir as decisões que, alinhadas aos recursos corporativos, ajudam a ligar as organizações ao seu ambiente (MILLER, 1998; PORTER, 1992). Dessa forma, os projetos relacionados a TI podem ser considerados como um recurso da empresa, que possui a capacidade de fomentar as estratégias da organização, no âmbito operacional, e direcioná-las para um patamar mais elevado, apoiando a organização na obtenção de vantagem competitiva (LUFTMAN, 1993; SABHERWAL e CHAN, 2001).

Segundo Laurindo et al. (2001, p. 175), é fundamental que haja uma visão estratégica comum, tanto para o negócio quanto para a área de TI da empresa.

Entretanto, o desafio do alinhamento entre as estratégias de negócio, com as estruturas internas de TI da empresa, não é um evento trivial nem isolado. Tampouco simples de ser obtido, pois se configura num processo dinâmico e contínuo.

Conforme Avison et al. (2004, p. 241), o desafio do alinhamento estratégico consiste na identificação e desenvolvimento de uma ferramenta prática aos gestores das empresas para auxiliá-los na avaliação do nível atual de alinhamento entre negócio e TI, além de controlar o alinhamento futuro.

A identificação das áreas que ajudam ou dificultam o alinhamento estratégico entre TI e negócios, baseado nas atividades da alta gestão para atingir as metas corporativas, foi objeto de análise em Luftman et al. (1999), que pesquisou os mais importantes facilitadores e inibidores desse alinhamento. A pesquisa desses autores apresentou dados obtidos a partir de informações comerciais de executivos de tecnologia, de mais de 500 empresas, que representavam mais de 15 indústrias. Os executivos foram solicitados a descrever as atividades que auxiliavam a realização do alinhamento estratégico na organização e também aquelas atividades que pareciam inibi-lo.

Em seguida, os autores denominaram as atividades que auxiliavam o alinhamento estratégico como facilitadoras; e aquelas que o dificultavam como inibidoras do alinhamento estratégico. Os resultados indicaram que certas atividades podem ajudar na realização do alinhamento, enquanto outras representam verdadeiras barreiras. Para Luftman et al. (1999), o alinhamento estratégico dentro da empresa é evolutivo e dinâmico, além de exigir um forte patrocínio da alta gestão.

Conforme Carr (2003, p. 3), a TI ocupa gradativamente um papel de destaque no delineamento da estratégia corporativa das empresas: "Presidentes de empresas agora falam rotineiramente sobre o valor estratégico da tecnologia da informação, sobre as diferentes maneiras de como utilizar a área de TI para ganhar vantagens competitivas".

Ainda, segundo Carr (2003, p. 9), o desafio estratégico de TI, em longo prazo, é gastar menos, mediante a utilização de soluções criativas. 
Segundo Avison et al. (2004, p. 225), o alinhamento estratégico entre negócio e TI pode auxiliar a empresa de três formas: (a) maximizando o retorno sobre investimento em TI; (b) ampliando a vantagem competitiva, por meio de sistemas de informação; e (c) fornecendo orientação e flexibilidade para reagir às novas oportunidades.

Conforme Teixeira e Souza (2013), uma empresa competitiva é aquela que domina os processos necessários ao seu negócio, mediante respostas ágeis e precisas, de forma a tornar-se mais flexível a fim de aproveitar as oportunidades do mercado. Ainda segundo os autores, competitividade é a capacidade de a empresa ser mais produtiva dentro de seu universo competidor.

$\mathrm{Na}$ visão tradicional, a criação de valor, ou a maximização do retorno sobre investimento, é obtida por meio da fabricação e troca de um bem ou serviço por dinheiro, outros bens ou outros serviços. Portanto, nessa situação, há uma clara distinção entre os papéis de produtores e consumidores. Porter (1980) propôs a criação de valor do produto conforme sua diferenciação, seu baixo custo ou sua abrangência no mercado, que poderia ser concentrada em nichos ou atingir todo esse mercado.

Para Araújo Júnior et al. (2013), pode-se conceituar a IC como o conjunto de ações sistemáticas e integradas de busca, processamento, análise e disseminação de informação que visam subsidiar os tomadores de decisão no ambiente corporativo.

Conforme Prescott e Miller (1999, p. 37), a IC é fundamental para ajudar o profissional de gestão na criação de respostas competitivas diante das novas oportunidades comerciais: "A finalidade de um programa de Inteligência Competitiva é desenvolver ações orientadas aos gestores. A IC também deve ser entregue em tempo hábil para que seja incorporada ao processo de tomada de decisão".

Ainda segundo o autor, o campo da IC passou por três etapas e está lutando para definir seu próximo estágio de desenvolvimento. A primeira etapa foi a "Aquisição da Inteligência Competitiva", que ocorreu entre as décadas de 1960 e 1970. A segunda etapa, que ocorreu na década de 1980, denomina-se: "Análise da Indústria e dos Concorrentes". A terceira etapa, que corresponde ao estágio de desenvolvimento atual, caracteriza-se como "Inteligência Competitiva para a Tomada de Decisão Estratégica".

Conforme Rouach e Santi (2001, p. 552), a Inteligência Competitiva permite à empresa compreender melhor o ambiente no qual está inserida. Para Arjol e Paul (2013), um conceito mais amplo de IC está ligado ao desenvolvimento da inteligência organizacional, ou seja, a capacidade de utilização das informações em processos organizacionais.

Segundo Vidigal (2013), a diversidade de aspectos ambientais externos, que precisam ser monitorados, exige um esforço significativo por parte dos gestores e tomadores de decisão. Nesse sentido, a Inteligência Competitiva é um instrumento importante para monitorar o ambiente externo, especialmente para minimizar as incertezas e criar valor de mercado por meio do ganho de competitividade.

Pepper, presidente da Procter \& Gamble, citado em Prescott e Miller (2002), refere-se à IC como Inteligência Empresarial. Ele considera a evolução da empresa associada intrinsecamente a três pontos fundamentais: $(i)$ atingir objetivos, mediante inovação; (ii) transformar ideias em ações; e (iii) capitalizar as tecnologias emergentes, a fim de potencializar a expansão do conhecimento. Ainda segundo Pepper, há cinco questões básicas envolvidas com a Inteligência Empresarial: razão de ser, estrutura, acesso à informação, uso do conhecimento e cultura. Pepper também afirma: "A Inteligência Competitiva deve coletar, analisar e disseminar conhecimentos e informações para criar estratégias vencedoras".

De acordo com Rouach e Santi (2001, p. 552), a IC rastreia as atividades dos concorrentes indiretos, como: atividade empresarial, desenvolvimento de negócios e estratégias variadas. Ainda segundo os autores, a IC coleta, processa e armazena informações para que sejam disponibilizadas a todos os níveis da empresa.

Deschamps e Nayak (1995) citam três tipos de Inteligência Competitiva:

- Inteligência de Mercado: fornece um roteiro das necessidades e preferências atuais e futuras dos clientes.

- Inteligência dos Concorrentes: avalia a evolução da estratégia competitiva ao longo do tempo, mediante: mudanças na estrutura dos concorrentes, (b) novos produtos substitutos e (c) nova indústria operadora.

- Inteligência Tecnológica: avalia o custo/benefício entre as tecnologias atuais e as novas. Além de prever futuras descontinuidades tecnológicas.

Para os autores, a inteligência competitiva pode ser ampliada, a partir dessas categorias, a fim de contemplar a quarta categoria de IC, Inteligência Estratégica e Social, com regulamentação financeira e fiscal, regulamentação econômica e 
questões políticas. Portanto, há espaço para uma aproximação entre a IC, o alinhamento estratégico entre negócio e os projetos de TI.

Os projetos de TI, assim como as soluções integradas, representam sistemas produtivos com alta variabilidade, baixa escala de produção e que atendem às necessidades específicas dos seus patrocinadores (BRADY et al., 2005).

O provedor de projetos de TI responsabiliza-se pela negociação com os múltiplos fornecedores, ou stakeholder do projeto, e adiciona valor ao produto de hardware/software. Assim, também passa a oferecer serviços (BRADY et al., 2005).

Segundo Hax e Wilde II (1999), as soluções integradas são mais que uma simples montagem, pois são adaptadas e precificadas de acordo com as necessidades específicas do cliente. A arquitetura das soluções integradas deve ser suficientemente robusta e flexível a fim de permitir sua adaptação à evolução dos requisitos de novos clientes, visando à economicidade do esforço organizacional necessário a cada novo projeto. Nesse contexto, tanto os fornecedores quanto os consumidores aplicam seus conhecimentos e habilidades na produção dos bens, e os clientes passam a utilizá-los em benefício próprio.

\section{Metodologia da Pesquisa}

A pesquisa formulada neste estudo classifica-se como exploratória, qualitativa, indutiva e foi conduzida por meio do método de estudo de caso. Para Yin (2010, p. 36), "O estudo de caso, como experimento, não representa uma 'amostragem' e ao realizar o estudo de caso, sua meta será expandir e generalizar teorias (generalização analítica) e não enumerar frequências (generalização estatística)". Segundo Martins e Theóphilo (2009, p. 62), o método de pesquisa do estudo de caso pede uma avaliação qualitativa. Ainda segundo Yin (2010, p. 32), o método de estudo de caso utiliza a observação direta.

O planejamento de um projeto de estudo de caso deve tratar de todo o processo da pesquisa: desde a questão principal, passando pelas premissas e proposições associadas ao estudo, construção do protocolo de pesquisa, coleta dos dados e evidências empíricas, até as conclusões e sugestões a respeito do caso estudado.

Assim, o pesquisador necessita traduzir o conceito genérico teórico numa relação com mundo real. Transpor a teoria à prática, a fim de explorar empiricamente esse conceito teórico. Essa transposição ocorre baseada em variáveis e fenômenos observáveis e denomina-se construto da pesquisa.

Dessa forma, a partir da formulação da questão principal da pesquisa e da revisão bibliográfica associada, o construto teórico foi evidenciado no Quadro 1. As respostas para a questão principal de pesquisa encontradas na literatura foram evidenciadas na forma de proposições (PRO), constituintes do instrumento de pesquisa.

Quadro 1: Proposições de estudo e questões de pesquisa associadas.

\section{Proposições}

PRO01. É necessário que a estratégia de negócios da empresa esteja alinhada com a estratégia de TI (MILLER, 1998; PORTER, 1992; LAURINDO et al., 2001).

Q1. A estratégia de negócios da empresa está alinhada à estratégia de TI?

PRO02. O provedor de projetos de TI responsabiliza-se pela negociação com os múltiplos fornecedores ou stakeholder dos projetos, e adiciona valor ao produto de hardware/software (BRADY et al., 2005).

Q2. O provedor de projetos de TI responsabiliza-se pela negociação com os múltiplos fornecedores?

Q3. O provedor de projetos de TI adiciona valor ao produto de hardware/software e, assim, também passa a oferecer serviços?

PRO03. Na Inteligência Competitiva, o valor é obtido mediante um inter-relacionamento, mutuamente benéfico, entre cliente e fornecedor (ROUACH e SANTI, 2001);

Q4. Ambas as partes, clientes e fornecedores, são cocriadoras desse valor? 
Para Yin (2010, p. 78), a escolha dos casos de um estudo de caso deve seguir uma lógica semelhante à lógica de seleção de diversas experiências de uma pesquisa experimental.

Por envolver o conceito Inteligência Competitiva, a escolha do caso foi feita a partir da dimensão considerada importante à condução das análises cruzadas: escritório de projetos consolidado que utilize técnicas de gerenciamento de projetos tradicional e empresa de TI, baseada no desenvolvimento de projetos, pertencente ao segmento econômico de prestadora de serviços de Tecnologia da Informação.

A contextualização da empresa participante do estudo de caso está evidenciada no Quadro 2.

Quadro 2: Contextualização da empresa participante da pesquisa.

\begin{tabular}{l} 
Empresa \\
\hline Atividade Econômica da Empresa: Prestadora de Serviços de Tecnologia da Informação \\
Tempo de Experiência no Mercado: 46 anos \\
Número de Funcionários: 1.800 \\
Tempo de Utilização das Técnicas de Gerenciamento de Projetos: 13 anos \\
Número de Projetos Implantados: mais de 50
\end{tabular}

O perfil do profissional entrevistado, além do método da coleta de dados realizada na Empresa 1, utilizada como unidade de análise do estudo de caso, está representados no Quadro 3.

Quadro 3: Detalhamento do perfil profissional do estudo de caso.

\begin{tabular}{|c|c|c|}
\hline Caso Referência & Entrevistado & Coleta de Dados \\
\hline Empresa 1 & $\begin{array}{l}\text { Gerente de Projetos (E1) } \\
\text { Especialista Gerencial (E2) } \\
\text { Coordenador Técnico (E3) }\end{array}$ & $\begin{array}{r}\text { Entrevista não estruturada, } \\
\text { mediante observação direta, } \\
\text { focada, com perguntas abertas, } \\
\text { gravada em meio digital, } \\
\text { tendo como base o protocolo } \\
\text { de pesquisa }\end{array}$ \\
\hline
\end{tabular}

A entrevista presencial realizada na Empresa 1 foi elaborada no formato espontâneo, focado e com duração média de uma hora. A entrevista ocorreu mediante formulação de questões abertas e estruturadas. O objetivo das perguntas abertas foi estimular o surgimento de novas ideias e criar a possibilidade de incrementar as proposições teóricas com proposições empíricas. A entrevista foi transcrita para o formato texto, a fim de auxiliar as anotações complementares realizadas pelo entrevistador. Segundo Yin (2010, p. 147), as anotações são um dos componentes mais comuns para o estudo de caso.

Para Martins e Theóphilo (2009, p. 68), a triangulação é o processo de corroboração dos dados de uma pesquisa por meio da comparação entre múltiplas fontes de evidências, a fim de obter maior qualidade e confiabilidade nos resultados.

\section{Análise dos Resultados}

Formulou-se uma ligação lógica entre a questão principal da pesquisa e as proposições desenvolvidas no estudo, mediante a identificação das hipóteses orientadoras do estudo de caso exploratório e das suas respectivas questões de pesquisa. Em seguida, efetuou-se a coleta das evidências empíricas e sua validação, para que servissem de subsídio à formulação das conclusões. Dessa forma, foi possível realizar inferências e finalmente elaborar o relatório final. As proposições serviram como base à análise do estudo de caso e auxiliaram na composição do roteiro da entrevista e do protocolo de pesquisa. Elas também foram baseadas nos conceitos teóricos fundamentais, encontrados a partir da revisão bibliográfica. 
Segundo a resposta do entrevistado E1, a estratégia de negócios da Empresa 1 está alinhada à sua estratégia de TI. Embora o desafio desse alinhamento não seja algo trivial, pois se configura num processo dinâmico e contínuo. Tal alinhamento tornou-se possível devido ao tempo de aplicação das técnicas de gerenciamento de projetos tradicional e ao seu grau de amadurecimento, pois a existência do Escritório de Projetos já completou treze anos. E como a atividade fim da Empresa 1 é o desenvolvimento de sistemas de informação, entende-se que, a partir do alinhamento estratégico entre negócios e TI, por meio da implantação de projetos, surge a capacidade de induzir as estratégias da organização até o âmbito de sua execução operacional, a fim de obter-se vantagem competitiva:

Eu acredito que sim. Porque, já que o negócio da empresa é prover soluções de tecnologia, então, dentro de um projeto que nós estamos conduzindo, ele tem como missão desenvolver uma solução para fazer a gestão dos serviços de tecnologia. De prover links para os órgãos do Estado. Então, eu acredito que esteja totalmente alinhada. O negócio da empresa versus a estratégia de TI. (E1)

Conforme a resposta do entrevistado E2, existe uma dependência entre as estratégias de negócio e TI na Empresa 1: "Sim. A visão e missão da empresa são totalmente dependentes de TI." (E2).

Vale ressaltar que todos os entrevistados trabalhavam na mesma empresa e constituíam partes complementares dos projetos, embora ocupassem cargos diferenciados, o que aparentemente influenciou decisivamente nas convergências entre as respostas sobre o alinhamento estratégico entre TI e negócios.

Para o entrevistado E3, não há alinhamento entre a estratégia de negócios e a estratégia de TI: "Não existe um processo formal de aprovação de demanda vinculado à estratégia da empresa.” (E3).

Essa negativa pode ser atribuída ao fato de o entrevistado não participar do processo de aprovação de novas demandas de negócio da Empresa 1, diferentemente dos entrevistados E1 e E2, que, além de participarem desse processo, também exercem funções gerenciais na empresa. Dessa forma, ambos os entrevistados, E1 e E2, detêm uma experiência prática mais orientada ao alinhamento entre as estratégias de negócio e de TI da Empresa 1.

Não houve contradição aparente na resposta do entrevistado E1. Entretanto, houve o acréscimo de um importante stakeholder em sua resposta, o fornecedor, que, segundo o entrevistado, foi envolvido na negociação de contratação pelo próprio provedor de serviço. Segue a resposta de E1:

Eu acredito que sim. Até porque, dentro das disciplinas de gestão de projetos, o gerente de projetos precisa gerenciar todos os participantes. Então, se há projetos onde não exista esse relacionamento com o fornecedor, eu não consigo dar andamento em determinadas atividades. Como exemplo, cito o projeto [...] de coleta de biometria. Havia um fornecedor, que deveria fazer ajustes no sistema, para que pudesse melhorar o serviço. Então, o próprio gerente de projetos, em conjunto com a área responsável de contratação, deu apoio no sentido de agilizar e fazer com que esse fornecedor fosse contratado o mais rápido possível. Então, por conta disso, eu acredito sim, que o provedor de TI, também participa dessa negociação. (E1)

Conforme o entrevistado E2 há o envolvimento de múltiplos fornecedores em todo o ciclo de vida do projeto, desde a sua concepção até finalmente sua implantação. Tal afirmação reforça a necessidade de se obter a vantagem competitiva na Empresa 1. Pois os fornecedores exercem um papel primordial ao longo de todo o projeto: "Sim. Para fazer a contratação, obter preços competitivos e para determinar a arquitetura da solução, são feitos contatos com fornecedores" (E2).

Entretanto, a nova negativa, observada na resposta do entrevistado E3 - "Não. Temos diversos exemplos de projetos que não obtiveram sucesso por problemas na definição de responsabilidades entre fornecedores" -, demonstra a sua constante divergência de opinião com os demais entrevistados, E1 e E2. Essa divergência poderia ser explicada pelo pouco envolvimento profissional do entrevistado E3, principalmente nas decisões estratégicas da Empresa 1. Portanto, o fato de E3 exercer uma função operacional o impediu de compreender o envolvimento prático de TI com a área de negócios e influenciou decisivamente suas respostas. Porém, esse distanciamento da estratégia da empresa não comprometeu sua capacidade de reconhecer a importância da influência exercida pelas partes interessadas sobre o sucesso nos projetos de TI.

Segundo o entrevistado E1, os projetos de TI atendem às necessidades específicas dos patrocinadores da Empresa 1. Portanto, são mais que uma simples montagem de software e hardware. Dessa forma, fornecedores e consumidores, aplicam seus conhecimentos, e habilidades, na produção dos bens, e os clientes passam a utilizá-los em benefício próprio. 
Assim, o valor migra do produto à rede de sistemas de informações, ou à rede social que engloba os vários interessados nesse bem ou serviço:

Eu acho que adiciona valor sim. Até porque nem todas as soluções da empresa, nós temos soluções só de ITO, que no caso, é toda a parte de infraestrutura. Nós temos soluções que podem ser só de APIS, que são aplicações. E podemos ter soluções que são as duas combinadas. Então, o hardware e software, e as duas não andam sozinhas. Até porque um dos negócios da empresa é desenvolver sistemas e hospedá-los aqui internamente. Então, está totalmente alinhado com infraestrutura [...], por exemplo, nós somos responsáveis por desenvolver [...] o sistema [...] que é utilizado pelos provedores de emissão da Carteira de Habilitação. Então, é uma solução que foi desenvolvida internamente por APIS, ela está hospedada aqui internamente, onde nós somos responsáveis pela infraestrutura. Então, essa parte de hardware. Onde nós agregamos mais? O produto desse sistema, por exemplo, é a pontuação na carteira, que nós a divulgamos atualmente por meio de aplicativos da Internet e Ipad. Então, nós fomos além do produto só hardware e só software. Nós agregamos, também, serviços, que de alguma forma, não está totalmente mensurado. Mas, gera uma satisfação no cliente [...] em contra partida, estimula e incentiva o próprio cliente a contratar outros serviços. (E1)

O provedor de projetos de TI agrega valor ao produto de software/hardware ao oferecer serviços para os clientes, conforme E2: "São criados produtos que além do uso interno podem ser oferecidos aos clientes" (E2).

Ao contrário da resposta de E3: "Não. A distância da área de negócios inviabiliza a criação de novos serviços" (E3).

O serviço prestado pela Empresa 1, juntamente com o valor percebido pelo cliente, consolida-se no resultado do projeto. Portanto, a empresa personaliza suas ofertas de bens ou serviços e esforça-se para aumentar a participação do cliente na personalização de seus serviços, embora alguns dos entrevistados reconheçam a necessidade de uma participação mais ativa dos fornecedores:

No [...] onde o cliente final é o cidadão, nós agregamos muito valor. Porque quando o cidadão vai até lá, para emitir um documento [...] nós proporcionamos esse valor, no sentido de resgatar a cidadania dele. Se pegarmos o sistema [...] de Boletim de Ocorrência, isso passa uma segurança ao cidadão. No sentido de estar sendo resguardado pelo Estado. Acho que, pela característica dos serviços da empresa, a área de projetos na qual atuamos, acaba conduzindo temas de projetos que vão além da necessidade do produto final, mas que realmente agregam valor para o cidadão. (E1)

\section{Conclusões}

Considerando os resultados da pesquisa descritos frente à literatura correlata, chega-se a algumas conclusões. Em primeiro lugar, conclui-se que não há características da Inteligência Competitiva (IC) associada ao alinhamento estratégico entre negócio e projetos de TI na empresa participante da pesquisa. Também se conclui que, após a finalização da pesquisa, a questão principal foi por demais abrangente e complexa para que pudesse ser respondida somente por um estudo de caso, realizado numa única empresa.

Assim, a formulação da questão, embora seja ambiciosa, tendo em vista o grau de profundidade da análise realizada pelo estudo, merece ser melhor estudada. Dessa forma, recomenda-se aos eventuais futuros estudos, advindos desta pesquisa, uma reflexão mais aprofundada sobre o alinhamento dos resultados alcançados, com os objetivos do estudo, para que sejam feitas as devidas adequações, a fim de apresentar um maior nível de clareza entre a IC, associada ao alinhamento estratégico entre negócio e projetos de TI. Finalmente, conclui-se que esta pesquisa teve o mérito de abordar um tema recente e assumir um desafio relevante, que sem dúvida merece um maior grau de aprofundamento.

\section{Referências}

ARAÚJO JÚNIOR, R. H.; PERUCCHI, V.; LOPES, P. R. D. Análise bibliométrica dos temas inteligência competitiva, gestão do conhecimento e conhecimento organizacional, no repositório institucional da universidade de Brasília.

Perspectivas em Ciência da Informação, [S.1], v. 18, n. 4, p. 54-69, out./dez. 2013.

ARJOL, M. G.; PAUL, L. M. Estrategias de gestón de la información asociadas a la inteligencia competitiva: apropiación en organizaciones de apoyo a empresas exportadoras. Visión de Futuro, [S.1], v. 17, n. 2, p. 147-167, jul. 2013.

AVISON, D. et al. Using and validating the strategic alignment model. Journal of Strategic Information Systems, [S.1]: v. 13, n. 3, p. 223-246, sep. 2004. 
BRADY, T. D. A.; GANN, D. M. Creating value by delivering integrated solutions. International Journal of Project Management, [S.1]: v. 23, n. 5, p. 360-365, jul. 2005.

CARR, N. G. TI já não importa. [S.1]: Harvard Business Review, 2003.

DESCHAMPS, J. P.; NAYAK, P. R. Product juggernauts. Boston: HBS Press, 1995.

HAMEL, G.; PRAHALAD, C. K. The core competence of the corporation. Reprint 90311. Harvard Business Review 1990, p. 3-15, 1990. Disponível em: <http://www.profrandes.com.br/wp-content/uploads/2013/03/Core-Competenceof-the-Corporation.pdf>. Acesso em: 13 maio 2014.

HAX, A. C.; WILDE II, D. L. The delta model: adaptive management for a changing world. MIT Sloan Management Review, [S.1], v. 40, n. 2, p. 11-28, jan. 1999.

HENDERSON, J.; VENKATRAMAN, N. Strategic alignment: a model for organisational transformation. In: Kochan, T.; Unseem, M. (Eds.), 1992. Transforming Organizations. OUP, New York, 1989. Disponível em: <http://www. wittenborg.eu/sites/default/files/files/imce/documents/misc/IT_revolution_strategicalignme90hend.pdf $>$. Acesso em: 23 de jun. 2014.

LAURINDO, F. J. B. et al. O papel da tecnologia da informação (TI) na estratégia das organizações. Gestão e Produção, São Carlos, v. 8, n. 2, p. 160-179, ago. 2001.

LUFTMAN, J. Transforming the enterprise: the alignment of business and information technology strategies. IBM Systems Journal, New York, v. 32, n. 1, p. 198-221, 1993.

LUFTMAN, J. et al. Enablers and Inhibitors of Business-IT Alignment. Communications of AIS, [S.1], v.1, n.1, 1999.

MARTINS, G. A.; THEÓPHILO, C. R. Metodologia da investigação científica para ciências sociais aplicadas. São Paulo: Atlas, 2009.

MILLER, D. Relating Porte's business strategies to environment and structure: analysis and performance implications. Ohio, Academy of Management Journal, v. 31, n. 2, p. 280-308, jun. 1988.

PORTER, M. E. Competitive strategy. New York: Free Press, 1980.

PORTER, M. E. Vantagem competitiva: criando e sustentando um desempenho superior. Rio de Janeiro: Campus, 1992. PRESCOTT, J. E.; MILLER, S. H. The evolution of competitive intelligence: designing a process for action. Proposal Management, Washington, Spring, v.21, n.4, p. 37-52, 1999.

ROUACH, D.; SANTI, P. Competitive intelligence adds value: five intelligence attitudes. European Management Journal, [S.1], v. 19, n. 5, p. 552-559, oct. 2001.

SABHERWAL, R.; CHAN, Y. E. Alignment between business and IS strategies: a study of prospectors, analyzers, and defenders. Information Systems Research, Linthicum, v. 12, n. 1, p. 11-33, mar. 2001.

TEIXEIRA, R. C.; SOUZA R. R. O uso das informações contidas em documentos de patentes nas práticas de inteligência competitiva: apresentação de um estudo das patentes da UFMG. Perspectivas em Ciência da Informação, Belo Horizonte - MG, v.18, n.1, p.106-125, jan./mar. 2013.

VIDIGAL, F. Inteligência competitiva: práticas funcionais, objetivos e infraestrutura em empresas no Brasil. Transformação, Campinas, v. 25, n.3, p. 237-243, set./dez. 2013.

YIN, R. K. Estudo de caso: planejamento e métodos. Porto Alegre: Bookman, 2010. 
Sobre o autor

\section{Cássio Chagas Montenegro Duarte}

Doutorado em andamento em Tecnologias da Inteligência e Design Digital na Pontifícia Universidade Católica de São Paulo, PUC/SP. Possui graduação em Tecnologia em Processamento de Dados, pela Universidade Presbiteriana Mackenzie (1989) e graduação em Engenharia Elétrica pela Pontifícia Universidade Católica de São Paulo (1999). Mestre em Administração pela Universidade Nove de Julho (2012). É professor adjunto no Centro Universitário Anhanguera. Atua como especialista de informática na Companhia de Processamento de Dados do Estado de São Paulo. Pesquisador nos temas: economias de repetição, conhecimento processual, arquitetura de sistemas, economias de recombinação $e$ organizações baseadas em projetos. 